\title{
Relevance, design experience and analysis of the results of point implementation of interdisciplinary courses in the educational process at the university
}

\author{
Yu. I. Lobanova \\ Saint Petersburg State University of Architecture and Civil Engineering (SPbGASU), \\ 4, 2nd Krasnoarmeyskaya, St. Petersburg, 190005, Russia
}

Received: August 2, 2021. Revised: August 30, 2021. Accepted: September 2, 2021. Published: September 6, 2021.

\begin{abstract}
The work points out the problems of adaptation of the subject to the activity and the possibility of their solution through the formation of the style of activity. The urgency of the use of non-subject resources for the formation of the style of activity in modern conditions is substantiated. The role of the engineer in creating the environment and means of labor, which can be used as extra- subject resources, is pointed out. The principles on which the professional training of engineers should be based, found on the need to solve the problems of "completing" the subject (the subject of labor, the subject of life activity) are indicated. The principles, on which the higher education is oriented, are analyzed, and the problems of the educational process in modern conditions are indicated. The importance of interdisciplinary courses in the training of engineers of the future is substantiated; the possibilities of their implementation in the educational process and the advantages and disadvantages are analyzed. The central part of the work is essentially a reflection of the process of design, development and in the depths of the interdisciplinary course "Introduction to Specialty", built on the basis of the disciplines chosen by the student "Psychology of Business Communication" and "Fundamentals of Business Communication and Presentation" in the educational process at a technical university, including analysis of feedback from students who took part in it. The results of the implementation of the course and its scaling for other levels and for other areas of training are presented. The article analyzes the assessments of the effectiveness of training, exhibited by students when filling out the feedback questionnaire, which indicates a high level of subjective assessment of the effectiveness of the course as a whole in the presence of certain differences in assessing the achievement of individual results by students of different areas of training. The main directions of further work are outlined. A
\end{abstract}

description of the structure and options for constructing a number of interdisciplinary courses is given.

Keywords-Style, resources, virtual environment, compensation, engineer of the future, interdisciplinary courses, implementation, scaling, subjective assessment, course effectiveness, information and communication technologies.

\section{THEORETICAL ANALYSIS}

A number of researchers working in different areas of psychological science and solving different problems have shown at different times that:

1. To reveal their potential, people strive to master different spheres of activity $[1,2]$

2. Different activities (especially professional types of activity), due to their specificity, impose different requirements on the professionally important qualities of candidates for the subjects and to the subjects of activity, and people, due to individual differences, in an unequal degree correspond to them $[2,3]$.

3. The problem of inconsistency can be partially solved through stylistic adaptation based on such mechanisms as adaptation, compensation and correction [2-4].

In Soviet psychology, in which the concept of an individual style of activity was born in the 50s of the last century, there was an attitude to the priority of the social environment, the special role of activity in the formation of personality. The ideology of equality was proclaimed. Training opportunities were provided. The overcoming of circumstances and difficulties by the individual was supported and encouraged. The concept of an individual style of activity (ISA), formulated by E. A. Klimov, perfectly fit into this context [3]. The very idea of ISA was based on the use of the subject's own (intraindividual, that is, intra-subject) resources, which were organized in a special way by the subject, allowing to achieve success in the activity, despite the inconsistency of 
individual qualities of the subject with the requirements of the activity.

So, for example, certain (underdeveloped) professionally important qualities of a driver can be compensated for through the formation of an individual style of activity with certain characteristics [5-7], in particular: an insufficiently high speed of switching attention is compensated within the planning style activities due to the reliance on long-term memory [6] and as a consequence of the reduction of the need to switch between the individual components of the driving activity; an underdeveloped linear and angular eye can be compensated by relying on the reflection of one's sensations and their memorization (while maintaining average confidence in the implementation of parking maneuvers) [7].

But the same problems of adaptation to activities due to the underdevelopment of certain professionally important qualities (if the driver is further considered as an object) can hypothetically be solved (and are already partially solved) through the use of extra- subject resources (environmental conditions), namely, at the expense of the use of modern technologies and technical systems used in the automotive industry [8-12]. If the subject has a bad long-term memory, then a navigator can come to his aid, if problems with reflection, then a parktronic or a camera will help. In other words, the ideas of adaptation to activity and in activity due to styles can be significantly transformed provided that style is considered as features of the subject's use of different resources ( intra, inter and outside of the subject [12] ) in the process of solving typical activity tasks and including such features in the analysis [13]. But at the same time, the very environment and conditions of activity, and the means of labor should provide such opportunities [13].

The solution of the problems of creating a subject environment, machines and intelligent systems - not replacing, but complementary, completing a person [14] - are tasks that will most likely have to be solved by engineers in the future . It seems that it is now in the external environment, primarily in the virtual (and in the assessment system) resources that have not been used by the subject until now. From this moment a new era may begin in which engineers will design and create physical and virtual reality in order to complete, complement a person, giving him perfection and allowing him not only to realize opportunities, but to make dreams come true.

But the onset of a new era will happen only if the training of engineers of the future takes place with a focus on the following principles [14]:

1) "Individualizations - engineering projects must be tailored to individual needs and with the goal of empowering those for whom they are intended. The created environment should both support and facilitate the manifestation of the individuality of its users.

2) Humanization - the creation of an artificial environment should be carried out according to the needs and requirements of persons with different potentialities and limitations, which implies ensuring their successful adaptation to life in society.
Full adaptation is possible only with the oncoming movement of the subject and the environment, which presupposes not only the adjustment of individual individuals to the requirements of the environment (both physical and social), but also a change in the environment as such.

3) Sustainability of professional decisions - this principle assumes the verification of decisions made from all sides of the design and production processes based on feedback in the form of expert assessments, including requests and assessments of future users of the product of engineering activity, which is possible only when the reflection of professional activity is formed as an element of the culture of professional thinking. at the stage of professional training"[18].

At this point in time, the educational process in Russia is changing its guidelines, gradually rebuilding itself to approaches that best meet modern realities, namely:

- $\quad$ project approach;

- systematic approach (based on the work of G.P. Shchedrovitsky) $[15,16,17]$;

- $\quad$ systems thinking [18];

- digitalization;

- focus on communication with production and work with customers.

However, not all universities are able to cope with the requirements of the time. And this despite the fact that some of them train bachelors and masters for the production sphere, in which such approaches are the only possible ones for existence and functioning [19]. For example, in the field of construction: objects are large-scale, can be unique, projects are in one way or another focused on specific customers and consumers, require the involvement of different specialists who are able to work effectively in a single team.

The purpose of this work is to identify a possible way of changes in the educational process in Russian universities by updating the internal resources they already have for the implementation of the above principles and approaches. The central part of the work is essentially a reflection of the design process, development and attempts to implement the author's interdisciplinary course, including the analysis of feedback from students who took part in it.

The idea of this pedagogical project appeared at the time of the transition of the Russian higher education system to a twostage one when working with the last graduates of the university who formally studied the optional discipline "Psychology of Business Communication" in a combined stream, which simultaneously studied students of two faculties and three different specialties.

This created a unique opportunity to unite children from different faculties and specialties into teams, giving them the opportunity to gain experience in project work with related specialists. In addition, individual teachers of the Department of Practical Psychology, leading this discipline, had an initial basic education in the field of industrial and civil construction and architecture, that is, they could partially take on the roles of project curators and experts.

At the same time, the teachers of the course had a clear 
understanding that any work on a project, especially a team work, requires interaction, that is, from a psychological point of view, it is impossible without effective communication.

If there are no fundamental problems with interaction, it is easy for a manager to organize work in a team using the required programs and principles (in the current realities, it is increasingly required to rely on the capabilities of agile and scrum) [20]. And if there is? Then you need to work with the mentality and with the setting of communication skills. And these are by no means purely managerial tasks, but essentially psychological ones [21].

And if you think about the widespread implementation of the project approach with working on projects in teams in close cooperation with the customer in universities, then without building effective communication between students with each other, with project curators, and curators - with students, other curators, other teachers acting in the role of experts, and customers, it will be simply unrealistic.

At the moment, the described system of interaction in our universities is poorly developed. Both traditional diplomas (and nowadays - graduation works of bachelors) basically presuppose the sole work of students on separate parts of projects, each of which is supervised by a teacher of a particular department. Diplomas are often a repetition of existing projects.

In other words, there is neither uniqueness nor practical significance of this kind of work. No teamwork proper - no students, no teachers. And students are forced to study it already in their workplaces, and teachers (especially for a long time not associated with production) simply do not get an idea about it.

Interdisciplinary courses, the central axis for which could be psychological and pedagogical disciplines [22] (primarily referring to "Psychology of business communication", "Fundamentals of business communication and presentation", "Social communications. Psychology"), could with these tasks to cope subject to the application of modern innovative psychological and pedagogical technologies within their framework [23, 24, 25], such as: business and role-playing games, in which conditions, tasks of activity and interaction between specialists are imitated, case-study [26, 27 ] (in focus on solving problems arising in the real production activity of a specialist), design in a team (with the organization of work based on different interaction technologies).

The essence of training within the framework of an interdisciplinary course is that when mastering certain psychological topics (for example, listening techniques, argumentation of a point of view, means of communication, negotiation, self-presentation, etc.), students turn, including to the profile subject content, gradually mastering interaction and work in teams, work on projects, and upon completion of the course, present the results of such to experts in the relevant fields. Wherein:

- degree of interdisciplinarity of the designed and implemented courses can be different (projects can acquire different components depending on which department's teachers can take over team management and expert assessment);

- subject content may be different (it will also be determined by the possibilities of connecting teachers of specialized disciplines and external experts to the course);

- projects that students carry out may have a different level of complexity (depending on the level of preparedness, the level of education, the abilities of the students themselves, the competencies of teachers and experts, the flexibility that all participants in the educational process are ready to show.

The advantages of this kind of courses can be:

- emergence of new interesting ideas, which can later be adopted by the trainees and teachers themselves - both in the preparation of graduate qualification works and - in the future - in research work.

- intensification of training and at the same time ensuring a better assimilation of educational material: in the presence of errors, trainees receive feedback from experts. Moreover, the analysis of errors is a connection, work on errors, a deeper assimilation of the material. And the mistakes not only of their own, but also of fellow students.

- provides a more flexible and effective management of motivation of trainees;

- more intensive and effective interaction between students and teachers is ensured, immersion in the professional environment is provided already at the stage of professional training, a circle of like-minded people appears, the ability to make sustainable professional decisions is formed by rechecking them from the standpoint of allied specialists.

The undoubted complexity of the creation and implementation of this kind of course lies in the need either to attract practically unique specialists to conduct courses (with education not in one, but in two or even three profiles), or to organize a rather complex interaction of all participants involved in the course. And the most difficult thing is the algorithmization of such courses and the assessment of the teaching load for each student and teacher. Probably, it is the last point that is the stumbling block for the wide implementation of interdisciplinary courses in the field of Russian education: the administration needs to provide a certain freedom to teachers and the presence of trust between all sides of the educational process, since the absence of a rigid framework creates opportunities that can be used in different ways. people with different moral and ethical levels.

\section{METHOD}

The logic of several interdisciplinary courses, designed for students of the level of preparedness and at different levels of education, was built in an orientation to the above ideas. Detailed design and partial implementation in the educational process was carried out in relation to the course "Introduction to Specialty".

It is assumed that all the technologies of the developed interdisciplinary courses are based on the design of classes based on the following three technologies (depending on the specific goals and objectives of the course, others can be connected, but the ones listed below are basic):

1. Elements of socio-psychological training and team 
building training - for all potential participants in the interdisciplinary course.

2. Game design - if possible, followed by a transition to design activities.

3. Role-playing and business games associated with the development of various professional roles and ending with expert assessments of the results.

The specificity of the game design assignments received by the students is determined by the peculiarities of their professional training. Thus, within the framework of this technology, both general and professional competencies of students are honed. In the case of giving the design process a more regulated character and subject to the participation of specialists from specialized departments in the work, one can approach the implementation of a full-fledged interdisciplinary course.

After completing the training, a survey of students was carried out in order to obtain feedback. The students were asked to evaluate the effectiveness of training within the course on a number of parameters.

\section{RESUlTS}

The trial course was carried out on a group of students graduating from specialist programs. 94 students took part in the survey: average age 20.6; 51 girls and 43 boys). The results obtained by processing the feedback questionnaires are presented in Table 2.

Table 1. Subjective assessment of the effectiveness of the course (based on feedback questionnaires)

\begin{tabular}{|c|c|c|}
\hline Estimated parameter & $\begin{array}{l}\text { Positive shifts } \\
\text { (improvement) }\end{array}$ & $\begin{array}{c}\text { Neutral } \\
\text { ratings (no } \\
\text { change) }\end{array}$ \\
\hline Public speaking skills & 60 & 40 \\
\hline 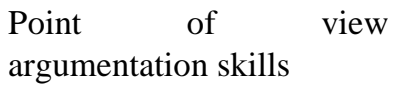 & 55.8 & 44.2 \\
\hline $\begin{array}{l}\text { Skills in using different } \\
\text { methods of psychological } \\
\text { influence }\end{array}$ & 48.4 & 51.6 \\
\hline $\begin{array}{l}\text { Recognition skills of } \\
\text { individual methods of } \\
\text { psychological influence in } \\
\text { a communication situation }\end{array}$ & 66.3 & 32,7 \\
\hline $\begin{array}{l}\text { Analysis of statements for } \\
\text { the detection of logical } \\
\text { violations in them }\end{array}$ & 80 & 20 \\
\hline $\begin{array}{l}\text { Recognition and defense } \\
\text { skills in situations of } \\
\text { uncivilized influence }\end{array}$ & 68.4 & 30.6 \\
\hline Teamwork skills & 69.5 & 29.5 \\
\hline $\begin{array}{l}\text { Relationships in the study } \\
\text { group }\end{array}$ & 32.6 & 67.4 \\
\hline $\begin{array}{l}\text { Defining your place in } \\
\text { teamwork }\end{array}$ & 32.6 & 67.4 \\
\hline $\begin{array}{l}\text { Determining your place in } \\
\text { the profession }\end{array}$ & 31.6 & 66.4 \\
\hline
\end{tabular}

Average percentage for all assessed parameters subjective effectiveness of 54.5 45.5 the course

The ratings were either positive (majority) or neutral. Later, in the course of the work, the possibilities of scaling the used approach and the psychological and pedagogical technologies used were tested - for use when working at the bachelor's level and for different areas of training. Below are the results of processing feedback questionnaires of students in two areas of training: construction and architecture.

The results presented in Table 3 were obtained by interviewing 1st year students (bachelor's level of preparation, direction of training "Construction"): 34 people, average age $18,2,30$ girls and 4 boys.

Table 2. Subjective assessment of the effectiveness of the course (based on feedback questionnaires)

\begin{tabular}{|c|c|c|}
\hline Estimated parameter & $\begin{array}{l}\text { Positive shifts } \\
\text { (improvement) }\end{array}$ & $\begin{array}{l}\text { Neutral } \\
\text { ratings } \\
\text { (no } \\
\text { change) }\end{array}$ \\
\hline Public speaking skills & 100 & 0 \\
\hline $\begin{array}{l}\text { Point of view argumentation } \\
\text { skills }\end{array}$ & 88.2 & 11.8 \\
\hline $\begin{array}{l}\text { Skills in using different } \\
\text { methods of psychological } \\
\text { influence }\end{array}$ & 82.4 & 17.6 \\
\hline $\begin{array}{l}\text { Recognition skills of } \\
\text { individual methods of } \\
\text { psychological influence in a } \\
\text { communication situation }\end{array}$ & 88.2 & 17.6 \\
\hline $\begin{array}{l}\text { Analysis of statements for the } \\
\text { detection of logical violations } \\
\text { in them }\end{array}$ & 88.2 & 11.8 \\
\hline $\begin{array}{l}\text { Recognition and defense skills } \\
\text { in situations of uncivilized } \\
\text { influence }\end{array}$ & 58.9 & 41.1 \\
\hline Teamwork skills & 94.1 & 5.6 \\
\hline $\begin{array}{l}\text { Relationships in the study } \\
\text { group }\end{array}$ & 82.3 & 11.8 \\
\hline $\begin{array}{l}\text { Defining your place in } \\
\text { teamwork }\end{array}$ & 64.7 & 29.4 \\
\hline $\begin{array}{l}\text { Determining your place in the } \\
\text { profession }\end{array}$ & 64.7 & 35.3 \\
\hline $\begin{array}{l}\text { Average percentage for all } \\
\text { assessed parameters - } \\
\text { subjective effectiveness of the } \\
\text { course }\end{array}$ & 81.2 & 18.8 \\
\hline
\end{tabular}

The results of comparative analysis show that the rate scale, designed for specialty, was a success: the percentage of positive responses of students who have studied at the undergraduate ( was higher than the average) than in the future experts. There were correspondingly fewer neutral responses, and no negative ones (as in the first case). 
Table 3

The results of a comparative analysis of the responses of students from the 1st and 2nd streams

\begin{tabular}{lccccc}
$\begin{array}{l}\text { Compared groups : } \\
\text { 1st and 2nd fluxes }\end{array}$ & Mean & $\begin{array}{c}\text { Average } \\
\text { differen } \\
\text { ce }\end{array}$ & $\begin{array}{c}\text { Standard } \\
\text { deviation }\end{array}$ & $\begin{array}{c}\text { Signifi- } \\
\text { cance } \\
\text { level }\end{array}$ \\
\hline $\begin{array}{l}\text { Average } \\
\text { value as a } \\
\text { percentage } \\
\text { of positive } \\
\text { responses }\end{array}$ & 1.00 & 54.5182 & -26.6500 & 16.61468 & 0 \\
\hline $\begin{array}{l}\text { Average } \\
\text { value as a } \\
\text { percentage } \\
\text { of neutral } \\
\text { responses }\end{array}$ & 2.00 & 81.1727 & & 13,08160 & \\
\hline
\end{tabular}

Table 4 presents the results obtained by interviewing 1 st year students (the level of preparation is undergraduate, the direction of training "Urban Planning"): 30 people, average age $18.5 ; 30$ girls.

Table 4. Subjective assessment of the effectiveness of the course (based on feedback questionnaires)

\section{Estimated parameter}

Public speaking skills

Point of view argumentation skills

Skills in using different methods of psychological influence

Recognition skills of individual methods of psychological influence in a communication situation

Analysis of statements for the detection of logical violations in them

Recognition and defense skills in situations of uncivilized influence

Teamwork skills

Relationships in the study group

Defining your place in teamwork

Determining your place in the profession

Average percentage for all assessed parameters subjective effectiveness of the course

The results of the comparative analysis show that the scaling of the course developed for students who studied in the direction of "Construction" (Faculty of Industrial and Civil Engineering), for another direction of training ("Urban Planning") (Faculty of Architecture), was also quite successful: the percentage of positive responses of students who studied at the bachelor's degree (on average) was higher than that of future specialists.

Nevertheless, the course seemed to be the most effective for students of the Faculty of Civil Engineering.

Correspondingly, there were fewer neutral responses, and no negative ones (as in the first case).

Table 5

The results of a comparative analysis of the responses of students from the 1 st and 3rd streams

\begin{tabular}{|c|c|c|c|c|c|}
\hline \multicolumn{2}{|c|}{$\begin{array}{l}\text { Compared groups: } \\
\text { 1st and 3rd fluxes }\end{array}$} & \multirow{2}{*}{$\frac{\text { Mean }}{54.5182}$} & \multirow{2}{*}{$\begin{array}{c}\begin{array}{c}\text { Average } \\
\text { difference }\end{array} \\
-14.1600\end{array}$} & \multirow{2}{*}{ 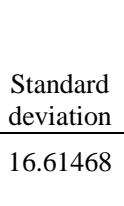 } & \multirow{2}{*}{$\begin{array}{l}\begin{array}{l}\text { Average } \\
\text { sq. error } \\
\text { of the } \\
\text { mean }\end{array} \\
5.00951\end{array}$} \\
\hline $\begin{array}{l}\text { Average } \\
\text { value as a } \\
\text { percentage }\end{array}$ & 1.00 & & & & \\
\hline $\begin{array}{l}\text { of positive } \\
\text { responses }\end{array}$ & 3.00 & 68.6818 & & 14.00292 & 4.22204 \\
\hline \multirow{2}{*}{$\begin{array}{l}\text { Average } \\
\text { value as a } \\
\text { percentage } \\
\text { of neutral } \\
\text { responses }\end{array}$} & 1.00 & 45.0273 & \multirow[t]{2}{*}{13.7000} & 16.59766 & 5.00438 \\
\hline & 3.00 & 31.3182 & & 14.00292 & 4.22204 \\
\hline
\end{tabular}

The results of a comparative analysis of the responses of students from the 2nd and 3rd streams

\begin{tabular}{|c|c|c|c|c|c|}
\hline \multicolumn{2}{|c|}{$\begin{array}{l}\text { Compared groups: } \\
\text { 2nd and 3rd fluxes }\end{array}$} & Mean & $\begin{array}{l}\text { Differences } \\
\text { in the mean }\end{array}$ & $\begin{array}{l}\text { Standard } \\
\text { deviation }\end{array}$ & $\begin{array}{c}\text { Average } \\
\text { sq. error } \\
\text { of the } \\
\text { mean }\end{array}$ \\
\hline $\begin{array}{l}\text { Average } \\
\text { value as a } \\
\text { percentage } \\
\text { of positive } \\
\text { responses }\end{array}$ & 2.00 & 81.1727 & 12,49 & 13.08160 & $\begin{array}{l}3.94425 \\
4.22204\end{array}$ \\
\hline $\begin{array}{l}\text { Average } \\
\text { value as a } \\
\text { percentage } \\
\text { of neutral } \\
\text { responses }\end{array}$ & 2.00 & 18.2545 & $-13,0600$ & 12.47472 & 3.76127 \\
\hline
\end{tabular}

\section{DISCUSSION}

Among the first-year students, there were even more positive assessments of the results obtained thanks to the course than among the senior students, which can be explained by both age-related characteristics (greater plasticity of the psyche, less pronounced criticality) and the moment of passing the course (in the senior years, the change in attitudes in study groups requires much more effort than on the younger ones, when the group dynamics is still very active), and the presence of a choice (students of the specialty discipline were offered as the only discipline, while undergraduate students had the opportunity to choose between two disciplines), which, apparently, also predetermined motivation trainees. Also, the idea of a place in the profession among senior students is often more formed, including due to the fact that most of them have 
work experience.

It should be noted that the students of the Faculty of Architecture were somewhat more critical of the results obtained, but at the entrance to the course itself, they expressed more fears than the builders, however, competent design and use of technology made it possible to create conditions in which the guys were able to get out of the "comfort zones", And work together, and acquire or hone a number of skills that will be very useful to them when participating in communications and - when presenting projects at public hearings and when working individually with clients. At the same time, the students of the Faculty of Architecture gave higher assessments of the effectiveness of the course in their main "painful" point - recognizing situations of uncivilized influence and practicing the skills of defense against such influences: students of this faculty, as representatives of the creative profession, are much more sensitive (in comparison with students of other faculties) to criticism, all the more to destructive criticism, training, according to students, allowed to significantly "build up" skills. The students of the Faculty of Civil Engineering, on the other hand, were clearly more focused on training the skills of providing psychological impact and public speaking: the course received the maximum efficiency ratings for these parameters.

\section{CONCLUSION}

In general, we can say that the results when scaling the course turned out to be even better than during the initial approbation of the course, which may be due not only to the age of students and their varying degrees of openness to new experience, motivation, psychological characteristics, but also active reflection experience in conducting courses by the developer himself and improving it on the basis of the same feedback questionnaires.

So, the course design and implementation were successful. It makes sense to move on to the development of other interdisciplinary courses focused on other goals, based on the already implemented. It remains only to overcome certain inertia of the education system, which traditionally relies on the fragmentation, independence of the work of individual departments and specific specialists. And translate the course into an online format, which will make it feasible even in the face of pandemics.

Finally, concerning the job prospects, if for the first years of the bachelor's degree, projects of the courses "Introduction to Specialty" and "Choice of Specialization" were offered, then for the senior courses of the bachelor's degree and (or) the master's level), courses may be offered aimed at the formation of professional psychological stability and the search for topics of final qualification and research work.

The description of these courses can be carried out in an orientation to the following structure: name, purpose, objectives, modules and their approximate content, psychological and pedagogical technologies used. Here are brief descriptions of the courses offered.

A. Course Title: "Introduction to Specialty"
1. Aim of the course: to help students in choosing a specialization within the framework of the construction profession.

2. Objectives of the course:

- formation motivation among trainees in relation to familiarization with the basics of certain specialized disciplines;

- creating conditions for group development through the issuance of special game tasks involving work in groups;

- creating conditions for trainees to perform certain professional roles within the framework of games that imitate certain aspects of professional activity;

3. Modules and their approximate content:

1) Psychological (mandatory) (necessary for psychological diagnostics, psychological assistance in building teams (and preventing problems of psychological incompatibility), building communications in a group, creating and maintaining a favorable psychological climate, helping in the development and use of group work technologies (with direct contact).

2) The rest are optional: in this case, only an expert assessment of the projects and ideas presented by the trainees is needed.

3) Technologies of individual classes: elements of social and psychological training (training of communicative competence), teamwork (game design), elements of creativity training, business game.

B. Course Title: "Choice of Specialization"

1. Aim of the course: to help students choose a specialization within the construction profession

2. Objectives of the course:

- conducting entrance vocational guidance diagnostics: diagnostics of a professional orientation, determining the type of personality, assessing the structure of intelligence, determining the preferred role in teamwork;

- $\quad$ creating conditions for group development by issuing assignments involving work in groups;

- creating conditions for trainees to perform certain professional roles within the framework of games that imitate certain aspects of professional activity;

- formation of motivation among students in relation to familiarization with the basics of specific specialized disciplines

3. Modules and their approximate content:

1) Psychological (necessary for conducting psychological diagnostics, providing psychological assistance in building teams (and preventing problems of psychological incompatibility), building communications in a group, creating and maintaining a favorable psychological climate, helping in the development and use of group work technologies (with direct contact).

2) Optional: for the direction of the bachelor's degree in the direction of "Construction" it can be such disciplines as: building materials, design disciplines (metal, reinforced concrete, wooden structures to choose from), construction production technology, production organization, economics, foreign language. 
This course will require an expert assessment of the projects and ideas presented by the trainees and the preliminary holding of the setting lectures by representatives of the relevant departments (to guide trainees in the search for literature, sites and the specifics of disciplines).

3) Technologies for conducting individual classes: elements of social and psychological training (training of communicative competence), teamwork (game design), elements of creativity training, business game.

C. Title of the Course: "Development of Reflection of Professional Activity and the Formation of Skills of Professional Interaction"

1. Aim of the course: creating conditions for the development of reflection of professional activity, that is, the development of trainees' ability to make sustainable professional decisions verified from all points of view.

2. Objectives of the course.

- creating conditions for the analysis of individual professional situations and decision-making from the position of a specialist of a certain profile;

- development of a reflexive mechanism (the formation of a professional worldview that facilitates decision-making after checking from different professional positions);

3. Modules and their approximate content:

1) Psychological (required)

2) Others by choice: this course option requires mandatory orientation lectures, the participation of specialized departments as experts in the final game, and (preferably) providing an opportunity for consultation on working on the details of projects and ideas. For the direction of the bachelor's degree in the direction of "Construction" it can be such disciplines as: building materials, design disciplines (metal, reinforced concrete, wooden structures to choose from), construction production technology, production organization, economics, and foreign language.

4. Technologies of individual lessons: gamepresentation, game design with the subsequent transition to project activities under the guidance of specialists from specialized departments, role-playing game "Tender" with ulterior motives, business game "Tender" with expert evaluations of works.

It remains only to overcome a certain inertia of the education system, which traditionally relies on the fragmentation, independence of the work of individual departments and specific specialists: when working on experimental projects, the author of the course faced various difficulties, first of all, in the issue of attracting experts (breakers from other departments), since participation this kind of work was not part of their academic workload. And one of the key points of the solution is to change the curricula and the teaching load of teachers in order to focus on such projects.

The developed course can be transformed - scaled for other purposes and for ragged levels of education, including graduate school. In these courses, psychology can act in a different way, allowing you to get closer to understanding the needs of users as customers of projects.
And translate the course into an online format, using the best practices in this area of other specialists [28-30] and taking into account the advantages and disadvantages of distance learning [31]. This will help to implement the course even in the face of pandemics.

\section{References}

[1] A. Maslou, The Far Reaches of the Human Psyche Spb: Evraziya, 1997, p. 430.

[2] V. A. Tolochek, Styles Activities: the Resource-Based Approach. Moscow: Publishing house «Psychology Institute RAN», 2015.

[3] E. A. Klimov, Individual Activity Style Depending on Typological Properties of the Nervous System. Kazan, 1969.

[4] E. P. Ilyin, "Activity style: New aspects and approaches". Psychology questions, no. 6, pp. 85-93, 1988

[5] Y. Lobanova, A Method of Designing an Efficient Individual Style of Activity for the Student Driver. In the collection: Transportation Research Procedia. 2018, pp. 440-445.

[6] J. Lobanova, "Psycological Factors Influencing Creation of Individual Driving Style Characteristics and Efficiency of Instructing on Practical Vehicle Driving". World Applied Sciences Journal, vol. 23, no.7, pp. 883-886, 2013.

[7] Y. I. Lobanova, Mechanisms of compensation of the driver's sense of dimensions Journal of Intellectual Disability - Diagnosis and Treatment, vol. 7, no. 4, pp. 265-273, 2019.

[8] S. V. Zhankaziev, K. A. Barinov, A. I. Vorobjev, M. G. Pletnyov and V. V. Dronsejko, "A Software Package for Pedagogical Workers who Train According to Adapted Vocational Training Programs for Drivers of Vehicles of the Corresponding Categories and Subcategories for Persons with Disabilities Certificate of Registration of the Program for EVM RU”. 2017662756, 16.11.2017. Application № 2017619504 from 22.09.2017.

[9] S. V. Zhankaziev, A. I. Vorob'ev and A. S. Polyakov, Modern trends in the development of intelligent transport systems. In the collection: "Modern Problems of Life Safety: Intelligent Transport Systems and Situational Centers. Collection of materials. In the International Scientific and Practical Conference". Office of the President of the Republic of Tatarstan, 2018, pp. 130-134.

[10] S. Zhankaziev, M. Gavrilyuk, D. Morozov and Zabudsky A Scientific and Methodological Approaches to the Development of a Feasibility Study for Intelligent Transportation Systems. In the collection. Transportation Research Procedia, 2018, pp. 841-847.

[11] V. Komashinskiy, I. Malygin and O. Korolev Introduction into cognitive multimodal transportation systems. In the collection: Transportation Research Procedia. 14. Cep. "14th International Conference on Organization and Traffic Safety Management in Large Cities, OTS 2020", 2020, pp. 273-279.

[12]I. Popova, E. Abdulina and I. Danilov, Intelligent driver assistance systems as factor of transportation safety assurance. In the collection: Transportation Research 
Procedia. 14. Cep. "14th International Conference on Organization and Traffic Safety Management in Large Cities, OTS 2020”. 2020, pp, 552-558.

[13] Yu. I. Lobanova, From the Age of Selection in the Era of Self-Actualization. Ed. A. N. Anohina, A. A. Oboznova, P. I. Paderno, S. F. Sergeeva (red.). Proceedings of the Third International Scientific and Practical Conference "The Human Factor in Complex Technical Systems and Environments" (Jergo-2018). SPb: LJeTI, 2018, pp. 574583.

[14] Y. I. Lobanova, "Basic guidelines, principles and psychological-pedagogical technologies of creation of the engineer of the future". Lecture notes in networks and systems, vol. 131, pp. 621-631, 2020.

[15] G.P. Shchedrovitsky Organizational and activity games as a form and method for the development of collective thinking and activity. Report at the Meeting on Business Games in Leningrad. 1982 // G.P. Shchedrovitsky. Organizational and activity game: a collection of texts. From the archive of G.P. Shchedrovitsky. T.9 (2). M., 2005

[16] G.P. Shchedrovitsky Problems of the development of applied psychology and organizational- activity games. Fragment of an unpublished article. 1985 // G.P. Shchedrovitsky. Organizational and activity game: a collection of texts. From the archive of G.P. Shchedrovitsky . Vol. 9 (2), M. 2005

[17] G.P. Shchedrovitsky Organizational- activity game as a new form and method of active teaching and upbringing in IPK universities // Development of applied psychological research and development. Abstracts of reports and messages at the scientific and practical conference. Krasnoyarsk - August 26-28, 1986 M., 1986

[18] Dennis Sherwood, 2002. This edition of "Seeing the Forest for the Trees: A Manager's Guide to Applying Systems Thinking" first published by Nicholas Brealey Publishing, London, 2002

[19] Ju. P. Bocharov and N. N. Zheblienok, "The Formation of Scientific Bases of Interaction of Different Disciplines in Urban Planning. In the Collection of Scientific Works of RAASN". Russian Academy of Architecture and Building Sciences. "Fundamental, Exploratory and Applied Research of the Russian Academy of Architecture and Construction Sciences for the Scientific Support of the Development of Architecture, Urban Planning and the Construction Industry of RF in 2018". Moskow: Ed. by ASV, 2019, pp. 222-230.

[20] Sutherland D. " Scrum . A Revolutionary Project Management Method" Publishing House: Mann, Ivanov and Ferber Series: MYTH. Business ISBN: 978-5-00146509-6 Year of publication: 2019 Number of pages: 288

[21]E. Klemenova, N. Berezina, A. Berezin, M. Ereshchenko and N. Kovalchuk "The scientific psychological knowledge in the structure of autocompetence of a student of a technical university as a factor in his professional development Lecture notes in networks and systems", vol. $131,2020$.

[22]A. Krupkin and Sinyakova, "Identification of relevant interactive teaching methods for the development of universal competencies of future engineers M". Lecture notes in networks and systems, vol. 131, pp. 652-658, 2020.

[23]L. Cherubini, "Exploring prospective teachers' critical thinking: Case-based pedagogy and the standards of professional practice". Teaching and Teacher Education, vol. 25, no. 2, pp. 228-234, 2009.

[24]P. Dillon, "Creativity, integrativism and a pedagogy of connection School of Education and Lifelong Learning". Thinking Skills and Creativity, vol. 1, no. 2, pp. 69-83, 2006.

[25]O. V. Mel'nikova, Training in the Process of Communication. In the Article in the Proceedings of the Conference SPb: SPbGASU, 2017, pp. 159-163.

[26] V. N. Kruglikov, M. V. Olennikova, N. A. Matveeva and O. O. Kunina, "Psychological training as a form of practical studies in the course introduction to the profession". Lecture notes in networks and systems, vol. 131, pp. 586-594, 2020.

[27]A. P. Panfilova, Game Management: Interactive Technologies for Training and Organizational Development of Personnel. SPb: IVJeSJeP, 2003.

[28] L. P. Kvashko, L. G. Aleksandrova, V. V. Shesternina, L. D. Erdakova and V. V. Kvashko, Distance learning during self-isolation: comparative analysis 12013. 1st international scientific conference "Asedu-2020: Advances in Science, Engineering and Digital Education". Journal of physics: conference series Krasnoyarsk Science and Technology City Hall. Type: collection of conference proceedings, Krasnoyarsk, vol. 1691, 08-09 October 2020.

[29] A. B. Orishev, A. A. Mamedov, D. V. Kotusov, S. L. Grigoriev and E. V. Makarova, "Digital education: vkontakte social network as a means of organizing the educational process 12092". Journal of physics: conference series Krasnoyarsk Science and Technology City Hall. Type: collection of conference proceedings, 1691.

[30] T. A. Makarenya, S. V. Stash and P. O. Nikashina, Modern educational technologies in the context of distance learning 12117. 1st international scientific conference "Asedu-2020: Advances in Science, Engineering and Digital Education". Journal of physics: conference series Krasnoyarsk Science and Technology City Hall. Type: collection of conference proceedings. Krasnoyarsk, vol. 1691, 08-09 October 2020.

[31] Yu. I. Lobanova, Distant studying experience reflection during pandemic of covid-19 (on the example of teaching in the technical university) 12152. 1st international scientific conference "Asedu-2020: Advances in Science, Engineering and Digital Education”. Journal of physics: conference series Krasnoyarsk Science and Technology City Hall. Type: collection of conference proceedings, Krasnoyarsk, vol. 1691, 08-09 October 2020.

\section{Creative Commons Attribution License 4.0 (Attribution 4.0 International, CC BY 4.0)}

This article is published under the terms of the Creative Commons Attribution License 4.0

https://creativecommons.org/licenses/by/4.0/deed.en_US 